\title{
On a new species of Mirograpsus Komai \& Fujita, 2018, from Vanuatu (Brachyura: Macrophthalmidae)
}

Peter K. L. Ng

\begin{abstract}
A second species of the ilyograpsine crab, Mirograpsus Komai \& Fujita, 2018 (Macrophthalmidae) is described from Vanuatu. It is compared to the type and only species, $M$. asper Komai \& Fujita, 2018, from Ryukyus in Japan, differing in the carapace shape, armature of the chelipeds and ambulatory legs, and structure of the male pleon.
\end{abstract}

LSIDurn:1sid:zoobank.org:pub:586C8C6C-7866-4F2D-97B2-4B52AED58F05

Key words: Ocypodoidea, taxonomy, new species, Mirograpsus, Ilyograpsinae, Vanuatu

\section{Introduction}

Among the unsorted thoracotreme specimens in the Lee Kong Chian Natural History Museum of the National University of Singapore collected during the 2006 SANTO expedition to Vanuatu (see Bouchet et al., 2009, 2011) is a small and unusual ocypodoid specimen collected from shallow waters. While superficially resembling a juvenile, it is actually an adult male. It is here described as the second species of the macrophthalmid Mirograpsus Komai \& Fujita, 2018 (Ilyograpsinae). The type and only species, M. asper Komai \& Fujita, 2018, was described from a single specimen from Ishigaki Island in the Ryukyus, Japan.

The terminology used follows $\mathrm{Ng}$ et al. (2008) and Davie et al. (2015). The material is deposited in the Zoological Reference Collection (ZRC) of the Lee Kong Chian Natural History Museum, National University of Singapore. Measurements, in millimetres, are of the maximum width and length, respectively. The abbreviations P2-P4 are used for the second to fourth pereopods ( = first to third ambulatory legs), respectively; G1 and G2 for first and second male gonopods, respectively.

\section{Taxonomy}

Family Macrophthalmidae Dana, 1851

Subfamily Ilyograpsinae Števčić, 2005

\section{Mirograpsus Komai \& Fujita, 2018}

\section{Type species}

Mirograpsus asper Komai \& Fujita, 2018, by monotypy.

\section{Remarks}

Komai \& Fujita (2018) discussed the taxonomy of Mirograpsus at length, and the author agrees that despite its unusual carapace and male pleonal features, is a macrophthalmid and best placed in the Ilyograpsinae Števčić, 2005 (see also Komai \& Wada, 2008; Naruse \& Kishino, 2006).

\section{Mirograpsus serratipes $\mathbf{n}$. sp.}

LSID urn:lsid:zoobank.org:act:0705D88EB954-4C26-A089-BF12AA6600A8

Figs. 1-3

\section{Material examined}

Holotype: male $(3.4 \times 3.9 \mathrm{~mm})($ ZRC 2018 . 


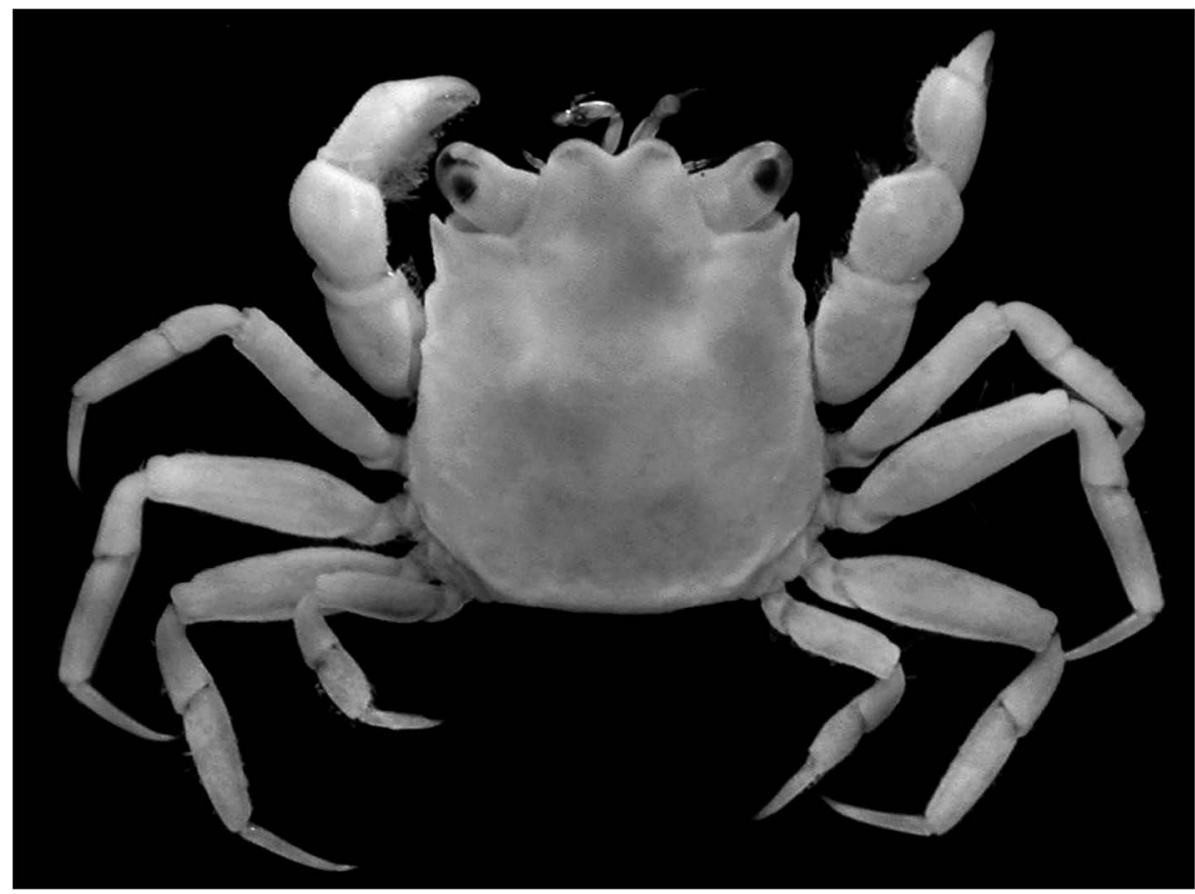

Fig. 1. Mirograpsus serratipes n. sp., holotype male $(3.4 \times 3.9 \mathrm{~mm})($ ZRC 2018.0758), Vanuatu. Overall habitus.

0758), station LD16, on white coral sand, Bruat Channel, northwest Ratua Island, $15^{\circ} 36.7^{\prime} \mathrm{S}$ $167^{\circ} 10.6^{\prime} \mathrm{E}, 5-6 \mathrm{~m}$, Vanuatu, coll. R.V. “Alis”, SANTO Expedition, 4 October 2006.

\section{Diagnosis}

Carapace with lateral margins almost straight, gently diverging towards posterior margin (Figs. 1, 2A); frontal margin distinctly produced anteriorly with margin of each lobe prominently convex (Figs. 1, 2A); external orbital tooth directed slightly obliquely laterally (Figs. 1, 2A); dorsal margins of carpus and chela of cheliped distinctly serrated (Figs. 2F, 3D); dorsal margins of ambulatory basis-ischium, merus, carpus and propodus with small sharp granules (Fig. 3E-H); surfaces of ambulatory dactylus smooth with no visible carinae (Fig. 3E-H); male pleon transversely broad, somites 4-6 fused, with lateral margins distinctly granulated.

\section{Description}

Carapace (Figs. 1, 2A) subquadrate, relatively flattened dorsally, width 0.87 times length; surface with microscopic granules; regions well defined, gastric, cardiac, intestinal and branchial regions prominently raised, hepatic regions slightly concave; cardiac region with 2 distinct prominences (Fig. 2B, C); branchial regions gently convex, each with distinct lateral tubercle laterally (Fig. 2C); gastro-cardiac grooves broad, distinct. Antero-and posterolateral margins not demarcated; lateral margins (Figs. 1, 2A) gently diverging throughout length towards posterior margin; widest between bases of P3. Lateral margin (Figs. 1, 2A) with 2 low lobes after external orbital tooth; external orbital tooth acutely triangular, directed slightly obliquely; first lobe well defined, margin convex, demarcated by wide clefts; second lobe very low, just discernible; margins not setose; surface adjacent to posterolateral margin with low, oblique granulated crest. 


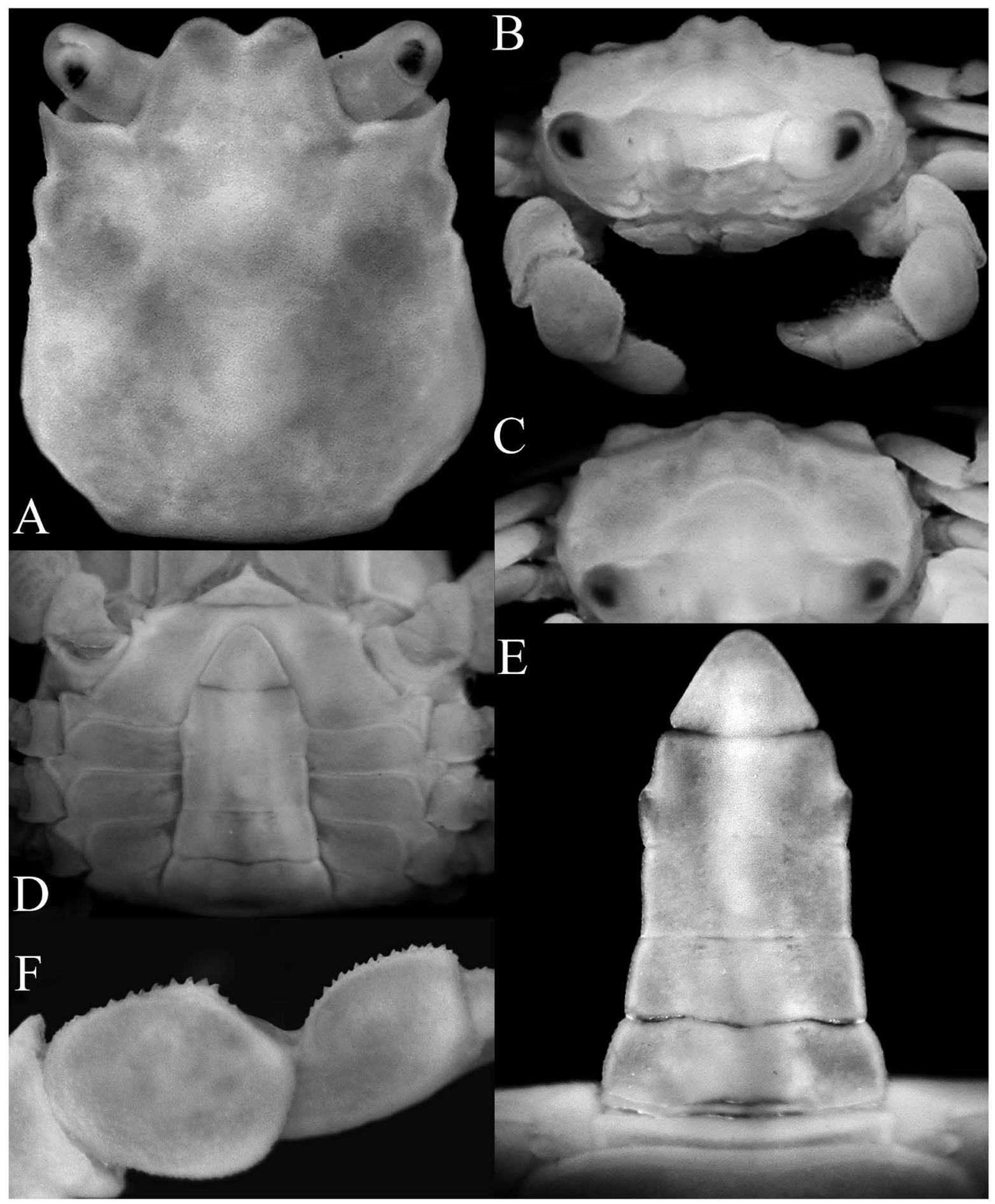

Fig. 2. Mirograpsus serratipes n. sp., holotype male $(3.4 \times 3.9 \mathrm{~mm})($ ZRC 2018.0758), Vanuatu. A, dorsal view of carapace; B, frontal view of cephalothorax; $\mathrm{C}$, dorso-frontal view of carapace; $\mathrm{D}$, thoracic sternum and pleon; E, pleon; $\mathrm{F}$, upper outer view of right carpus and chela. 

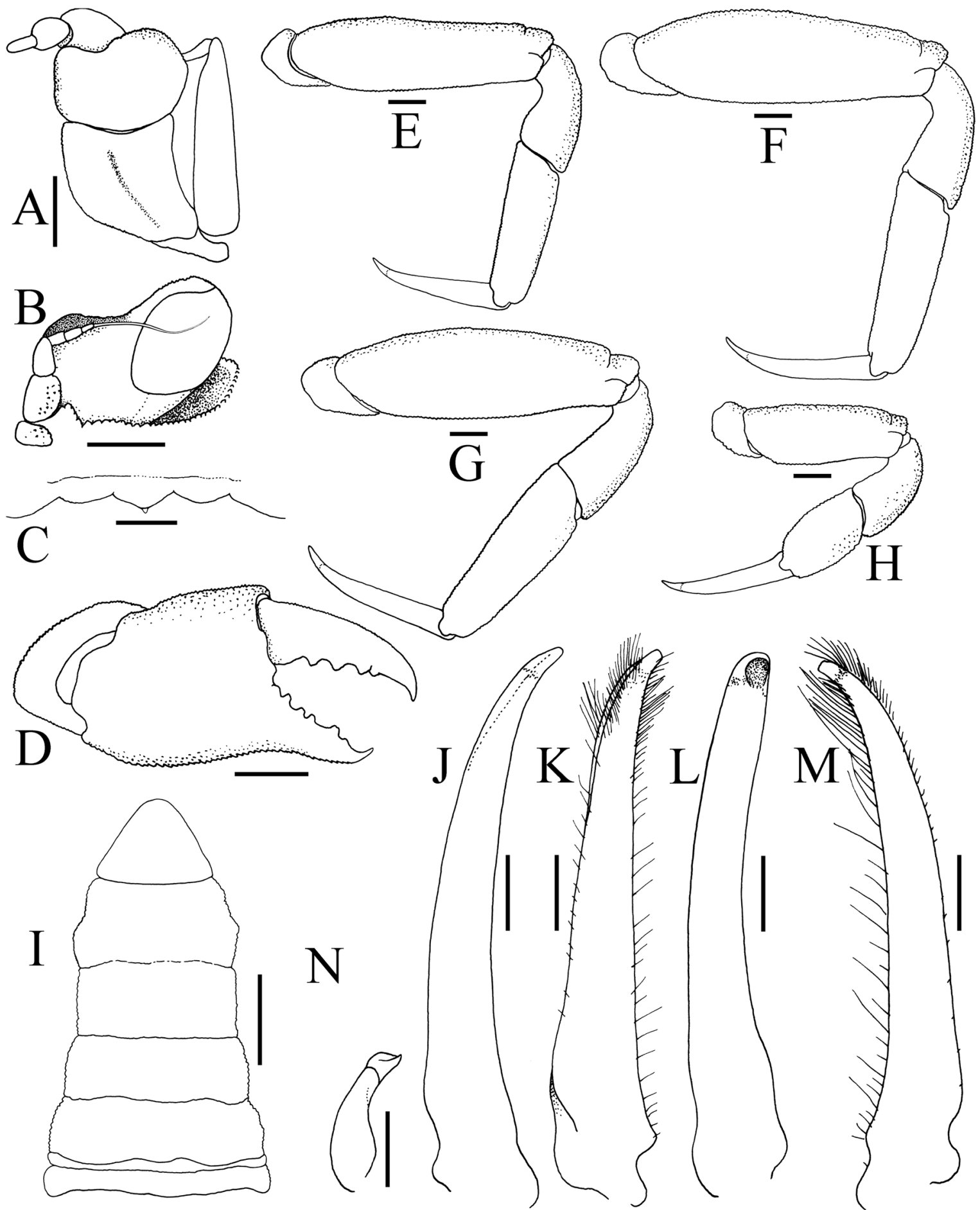

Fig. 3. A, left third maxilliped; B, left antenna, orbit and eye; C, posterior margin of epistome; D, outer view of right chela (setae not drawn); E-H, P2-P5, respectively (setae not drawn); I, pleon; J, left G1 (ventral view, setae not drawn); K, left G1 (subventral view); L, left G1 (outer mesial view, setae not drawn); M, left G1 (dorsal view); N, left G2. Scales: A-H, J-N =0.2 mm; I=0.5 mm. 
Front (Fig. 2A) prominent, distinctly produced anteriorly, bilobed, each lobe with strongly convex margin, separated by wide cleft; confluent with supraorbital margin; postfrontal lobes not discernible. Supraorbital margin (Fig. 2A) gently sinuous, transverse; infraorbital margin (Fig. 3B) gently convex in ventral view, lined with small rounded granules; inner orbital tooth (Fig. 3B) blunt, small, separated from infraorbital margin by small cleft. Pterygostomial region covered with small granules, with low oblique ridge that reaches anterolateral angle of buccal cavity. Eyes (Fig. 2A, B, 3B) large, touching external orbital tooth when retracted, slightly constricted medially; cornea ovate, nearly as long as peduncle; dorsal surface covered with small granules. Antennules (Fig. 3B) separated by narrow triangular septum; basal article large, swollen; flagellum folding slightly obliquely. Antennae (Fig. 3B) short, lodged in orbital hiatus; basal antennal article (= articles 2 and 3) subquadrate, covered with small granules, flagellum short, entering orbit, just reaching tip of cornea. Epistome (Fig. 3C) broad, posterior margin with 3 low triangular lobes, median lobe with tip relatively acute. Short endostomial ridges visible.

Third maxillipeds (Fig. 3A) completely closing buccal cavity, without trace of rhomboidal gap; ischium subquadrate, separated from basis by shallow groove, outer surface with minute granules, shallow oblique median sulcus; merus wider, shorter than ischium, surface with small granules, anteroexternal angle expanded to form auriculiform structure; inserted on inner subdistal surface of merus, propodus and dactylus. Exopod (Fig. 3A) relatively slender, width less than half of width of ischium, reaching to two-thirds length of merus, flagellum long, with 2 articles, reaching width of merus.

Chelipeds (Figs. 1, 2B) subequal, similar. Ischiobasis with inner surface swollen, granular. Merus covered with granules except for inner surface; inner surface gently concave, smooth, with row of short setae on subventral margin; upper margin carinate, gently convex, lined with small granules, with shallow subdistal notch. Carpus (Fig. 2F) round, without inner distal angle; surfaces covered with small granules; outer surface convex; dorsal margin with prominent sharp granules; inner surface with small patch of short setae dorsally. Chela (Figs. $2 \mathrm{~F}, 3 \mathrm{D})$ relatively robust; upper and outer surfaces granular; dorsal margin with low carina, lined with sharp granules; ventral margin (including pollex) weakly carinate, gently sinuous; inner surface with long plumose setae; fingers sharp, tip crossing; cutting margins with small triangular teeth.

Ambulatory legs (Figs. 1, 3E-H) moderately long, relatively slender; P3 and P4 longest, P5 shortest; surfaces of meri, carpi and propodi with small granules, more prominent on dorsal and subdorsal surfaces. Merus (Fig. 3E-H) widest medially, those of second and third legs widest; dorsal margin lined with small granules, appears gently serrated, without dorsal subdistal tooth or spine; margins with scattered setae. Carpus (Fig. 3E-H) with dorsal margin distinctly granulated, without obvious ridges. Propodus (Fig. 3E-H) laterally flattened, gently narrowing distally, with scattered or no setae. Dactylus (Fig. 3E-H) slender, gently curved distally, terminating in corneous claw, surface smooth, without carinae.

Thoracic sternum (Fig. 2D) moderately wide. Sternites $1 / 2$ (Fig. 2D) completely fused, triangular; separated from sternite 3 by deep, straight transverse groove. Sternites 3/4 (Fig. 2D) fused, demarcated by very shallow grooves. Suture between sternites $4 / 5$ slightly sinuous; sutures between sternites 5/6, 6/7 and $7 / 8$ nearly straight. Sternopleonal cavity (Fig. 2D) reaching just beyond margin of sternites $3 / 4$; press-button of pleonal locking mechanism with small knob on anterior edge of thoracic sternite 5. Penis sternal, not calcified.

Pleon (Figs. 2E, 3I) subquadrate, somites 2-5 gently narrowing toward telson. Somite 1 (Fig. 3I) widest, not reaching coxae of P5, sep- 
arated by small part of sternite 8 . Somite 2 (Fig. 3I) very narrow longitudinally. Somite 3 (Fig. 3I) subtrapezoidal, lateral margins convex, granulated. Somites 4-6 (Fig. 3I) functionally fused, sutures shallow, barely visible; lateral margins granulated; lateral margin of somite 6 with median part projecting laterally. Telson triangular (Fig. 3I), tip rounded.

G1 (Fig. 3J-M) not reaching midlength of sternite 4, slightly curved outwards, tapering gradually distally to short chitinous process, cup-like in mesial view; subdistal surface with long setae which obscures margins. G2 (Fig. $3 \mathrm{~N})$ less than one-fifth length of G1, C-shaped, distal part spatuliform.

\section{Etymology}

The name alludes to the serrrated margins of the cheliped carpus and palm. The name is used as a noun in apposition.

\section{Remarks}

Mirograpsus serratipes n. sp. differs from $M$. asper in the following characters: the carapace has the lateral margins almost straight and diverging towards the posterior margin (Figs. 1, 2A) (versus lateral margins gently convex and subparallel in M. asper; Komai \& Fujita, 2018: figs. 1, 2A); the frontal margin is more produced anteriorly with the margin of each lobe prominently convex (Figs. 1, 2A) (versus frontal margin less produced anteriorly with each lobe gently convex and less prominent in $M$. asper; Komai \& Fujita, 2018: figs. 1, 2A); the external orbital tooth is directed slightly obliquely laterally (Figs. 1, 2A) (versus directed distinctly anteriorly in $M$. asper; Komai \& Fujita, 2018: figs. 1, 2A); the dorsal margins of the carpus and chela of the cheliped as well as the ambulatory basis-ischium, merus, carpus and propodus are distinctly serrated (Figs. 2F, 3D-H) (versus smooth or lined only with minutes granules in $M$. asper; Komai \& Fujita, 2018: figs. 4); the surfaces of the ambulatory dactylus are smooth with no discernible carina
(Fig. 3E-H) (versus ambulatory dactyli with distinct rows of carinae in $M$. asper; Komai \& Fujita, 2018: fig. C-F); and the male pleon is proportionately broader transversely with the lateral margins distinctly granulated (Figs. 2E, 3I) (versus pleon proportionately more narrow with the lateral margins almost smooth in $M$. asper; Komai \& Fujita, 2018: fig. 2G). The serrations on the ambulatory meri and cheliped carpus and chela are especially prominent, and clearly absent in $M$. asper (T. Komai, personal communication).

Mirograpsus asper was obtained from an intertidal sand and mud flat with a small adjacent river and mangroves in Ishigaki Island, Ryukyus, Japan (Komai \& Fujita, 2018). Mirograpsus serratipes was collected on coral sand from subtidal waters 5-6 $\mathrm{m}$ deep. Considering their habitat which is easily sampled, it is surprising Mirograpsus has not been discovered until recently. It is likely that many samples of Mirograpsus have been collected but mistakenly believed to be juvenile grapsoids due to their small size.

\section{Acknowledgements}

The new species was collected during the 2006 SANTO expedition to Vanuatu organised by the Muséum national d'Histoire naturelle in Paris (Philippe Bouchet lead) and the Vanuatu Department of Fisheries, and partially funded by TOTAL Foundation and various organisations. Thanks are due to Tomoyuki Komai for kindly checking on some of the characters of $M$. asper to confirm the differences discussed here. His comments and those of Tohru Naruse of the draft manuscript are much appreciated.

\section{Literature cited}

Bouchet, P., Le Guyader H., \& Pascal O., 2009. The SANTO 2006 Global Biodiversity Survey: an attempt to reconcile the pace of taxonomy and conservation. Zoosystema, 
31(3): 401-406.

Bouchet, P., Le Guyader, H., \& Pascal, O. (eds.) 2011. The Natural History of Santo. Muséum national d'Histoire naturelle, Paris; IRD, Marseille ; Pro-Natura International, Paris, 572 pp.

Dana, J. D., 1851. Conspectus crustaceorum quae in orbis terrarum circumnavigatione, Carolo Wilkes e classe Reipublicae Foederatae Duce, lexit et descripsit J. D. Dana. Crustacea Grapsoidea, (Cyclometopa, Edwardsii). Proceedings of the Academy of Natural Sciences of Philadelphia, 5: 247-254.

Davie, P. J. F., Guinot, D., \& Ng, P. K. L., 2015. Anatomy and functional morphology of Brachyura. In: Castro, P., Davie, P. J. F., Guinot, D., Schram, F. R., \& von Vaupel Klein, J. C. (eds.), Treatise on ZoologyAnatomy, Taxonomy, Biology. The Crustacea. Volume 9C-I. Decapoda: Brachyura (Part 1), pp. 11-163.

Komai, T., \& Fujita, Y., 2018. A new genus and new species assigned to Macrophthalmidae (Decapoda: Brachyura: Thoracotremata) from the Ryukyu Islands, Japan. Zootaxa, 4531(1): 109-116.

Komai, T., \& Wada, K., 2008. A revision of the estuarine crab genus Ilyograpsus Barnard,
1955 (Crustacea: Decapoda: Brachyura: Macrophthalmidae), with descriptions of a new genus and one new species. Raffles Bulletin of Zoology, 56(2): 357-384.

Naruse, T., \& Kishino, T., 2006. New species of Ilyograpsus from the Ryukyu Islands, Japan, with notes on I. nodulosus Sakai, 1983. Crustacean Research, 35: 67-78.

Ng, P. K. L., Guinot, D., \& Davie, P. J. F., 2008. Systema Brachyurorum: Part I. An annotated checklist of extant brachyuran crabs of the world. Raffles Bulletin of Zoology, Supplement 17: 1-286.

Stevčić, Z., 2005. The reclassification of Brachyuran Crabs (Crustacea: Decapoda: Brachyura). Natura Croatica (Fauna Croatica), 14(1): 1-159.

\section{Address}

(PKLN) Lee Kong Chian Natural History Museum, National University of Singapore, 2 Conservatory Drive, Singapore 117377, Republic of Singapore.

\section{E-mail address}

peterng@nus.edu.sg 